\title{
Effects of extended-release niacin/ laropiprant on correlations between apolipoprotein B, LDL-cholesterol and non-HDL-cholesterol in patients with type 2 diabetes
}

Eliot A. Brinton 1*, Joseph Triscari², Philippe Brudi², Erluo Chen², Amy O. Johnson-Levonas², Christine McCrary Sisk², Rae Ann Ruck', Alexandra A. MacLean², Darbie Maccubbin² and Yale B. Mitchel ${ }^{2}$

\begin{abstract}
Background: LDL-C, non-HDL-C and ApoB levels are inter-correlated and all predict risk of atherosclerotic cardiovascular disease (ASCVD) in patients with type 2 diabetes mellitus (T2DM) and/or high TG. These levels are lowered by extended-release niacin (ERN), and changes in the ratios of these levels may affect ASCVD risk. This analysis examined the effects of extended-release niacin/laropiprant (ERN/LRPT) on the relationships between apoB:LDL-C and apoB:non-HDL-C in patients with T2DM.

Methods: T2DM patients $(n=796)$ had LDL-C $\geq 1.55$ and $<2.97 \mathrm{mmol} / \mathrm{L}$ and $\mathrm{TG}<5.65 \mathrm{mmol} / \mathrm{L}$ following a 4-week, lipid-modifying run-in ( $78 \%$ taking statins). ApoB:LDL-C and apoB:non-HDL-C correlations were assessed after randomized (4:3), double-blind ERN/LRPT or placebo for 12 weeks. Pearson correlation coefficients between apoB:LDL-C and apoB:non-HDL-C were computed and simple linear regression models were fitted for apoB:LDL-C and apoB:non-HDL-C at baseline and Week 12, and the correlations between measured apoB and measured vs predicted values of $L D L-C$ and non-HDL-C were studied.

Results: $L D L-C$ and especially non-HDL-C were well correlated with apoB at baseline, and treatment with ERN/LRPT increased these correlations, especially between LDL-C and apoB. Despite the tighter correlations, many patients who achieved non-HDL-C goal, and especially LDL-C goal, remained above apoB goal. There was a trend towards greater increases in these correlations in the higher TG subgroup, non-significant possibly due to the small number of subjects.
\end{abstract}

Conclusions: ERN/LRPT treatment increased association of apoB with LDL-C and non-HDL-C in patients with T2DM. Lowering LDL-C, non-HDL-C and apoB with niacin has the potential to reduce coronary risk in patients with T2DM.

Keywords: Extended-release niacin/laropiprant, Type 2 diabetes mellitus, ApoB, LDL-C and non-HDL-C

Abbreviations: apoB, apolipoprotein B; apoB:LDL-C, apoB and LDL-C; apoB:non-HDL-C, apoB and non-HDL-C; ASCVD, atherosclerotic cardiovascular disease; CHD, coronary heart disease; ERN/LRPT, extended-release niacin/ laropiprant fixed-dose combination; HDL-C, high-density lipoprotein cholesterol; LDL-C, low-density lipoprotein cholesterol; T2DM, type 2 diabetes mellitus; TG, triglyceride (s)

\footnotetext{
* Correspondence: eliot.brinton@utah.edu

${ }^{1}$ Division of Atherometabolic Research, Utah Foundation for Biomedical

Research, 420 Chipeta Way, Room 1160, Salt Lake City, UT 84108, USA

Full list of author information is available at the end of the article
} 


\section{Highlights}

- LDL-C, ApoB and non-HDL-C are markers of coronary risk.

- Niacin reduces LDL-C, ApoB and non-HDL-C, with or without concurrent statin treatment.

- Statins increase the strength of correlations of $A p o B$ with LDL-C and non-HDL-C.

- We studied the effects of niacin on these correlations in patients with diabetes.

- Niacin also increased the strength of correlations of ApoB with LDL-C and non-HDL-C.

\section{Background}

The prevalence of type 2 diabetes mellitus (T2DM) is high. In 2010, an estimated 19.7 million Americans, $8.3 \%$ of the adult population, had diagnosed T2DM [1]. An additional 8.2 million Americans had undiagnosed T2DM, and $38.2 \%$ had pre-diabetes, with abnormal fasting glucose levels [1]. Patients with T2DM have a two- to four-fold elevated risk of cardiovascular disease relative to people without diabetes [2]. The dyslipidemia commonly associated with T2DM is typified by elevated plasma triglycerides (TG), low high-density lipoprotein cholesterol (HDL-C) levels, and a preponderance of small, dense lowdensity lipoprotein (LDL) particles [3].

Aggressive treatment of dyslipidemia is recommended for patients with T2DM to reduce coronary heart disease (CHD) risk, with the cornerstone of treatment being statin therapy. The Third Report of the National Cholesterol Education Program Expert Panel on Detection, Evaluation, and Treatment of High Blood Cholesterol in Adults (NCEP ATP-III) suggested treatment to achieve a lowdensity lipoprotein cholesterol (LDL-C) goal $<2.59 \mathrm{mmol} / \mathrm{L}$ and optionally $<1.81 \mathrm{mmol} / \mathrm{L}$, with corresponding goals for non-high-density lipoprotein cholesterol (non-HDL-C) of $<3.36 \mathrm{mmol} / \mathrm{L}$ and $<2.59 \mathrm{mmol} / \mathrm{L}$, respectively, in patients with the highest CHD risk [4-8]. In November 2013, the American College of Cardiology and American Heart Association (ACC/AHA) released cholesterol guidelines which did not endorse LDL-C and non-HDL-C treatment goals [9], but this deletion has been rejected by several professional national and international societies [10-12]. Further, it is important to note that the NHLBI, which had sponsored the lengthy data review and writing efforts (completely independent of the ACC and AHA), decided at the end of these processes that the resulting document should be published simply as an "evidentiary review." [13] For this reason, it seems inappropriate that subsequent cursory ACC/AHA review and approval of the NHLBIderived document be considered to have produced an official US guideline. Thus, primary reliance on lipid goals continues to be quite reasonable in clinical practice worldwide. Finally, despite the fact that the main lipid guideline emphasis traditionally has been on LDL-C, recent evidence suggests that apolipoprotein (apo) B and non-HDL-C may be better indicators of CHD risk, especially for patients with T2DM and/or elevated TG [14-19].

Many patients with T2DM fail to reach their LDL-C, non-HDL-C and apoB goals with statin therapy alone, in which case combination therapy with other lipidmodifying agents has been suggested $[4,5,7,8,20]$. Niacin (nicotinic acid) is a lipid-modifying agent that lowers LDL-C, apoB, non-HDL-C and TG levels and raises HDL-C levels. The combination of statins and niacin produces additive and complementary effects on plasma lipid/lipoprotein profiles. Previous clinical trials demonstrated that niacin monotherapy reduced myocardial infarction at 5 years and cardiovascular mortality at 15 years and, in combination with other lipid-modifying therapies (statins, bile acid resins, or both), slowed progression/induced regression of atherosclerotic plaque in patients with cardiovascular disease [21-24]. In contrast, two recent coronary outcomes trials failed to show that the addition of extended release niacin (ERN) to statin monotherapy further reduced cardiovascular events in patients with established cardiovascular disease and low baseline LDLC levels, at least in the overall study populations [25, 26]. Subgroups with greater dyslipidemia, however, were noted to benefit [26, 27]. Further, niacin remains a treatment option for certain disease states and specific patient groups (e.g., statin-intolerant patients). Although niacin may not be used extensively for the treatment of patients with T2DM due to its tendency to worsen glycemic control, it is a reasonable choice in T2DM patients who are statin-intolerant and who have well-controlled plasma glucose levels.

\section{Objective}

Several studies have evaluated the effects of statin therapy on the relationships (i.e., correlations and concordances) between apoB:LDL-C and apoB:non-HDL-C [28-34], and a recent study showed increasing strength in these correlations following treatment with either ERN/LRPT, a statin, or their combination [35]. A recent meta-analysis of statin trials found that on-treatment non-HDL-C and apoB and LDL-C all predicted subsequent cardiovascular events, and non-HDL-C was the best predictor among them [14]. The effect of ERN (with or without laropiprant) on apoB:LDL-C and apoB:non-HDL-C has not been investigated to date in patients with T2DM.

This study is a post-hoc analysis of a previously published clinical trial of ERN in combination with the flushing pathway inhibitor, laropiprant (ERN/LRPT), which significantly improved LDL-C, HDL-C and TG levels in patients with T2DM [36]. Although ERN/LRPT has been associated with a statistically significant increase in the incidence of certain non-fatal serious adverse events [26] and, therefore, has been withdrawn from the market and 
from further clinical development, laropiprant did not appear to alter the lipid effects of ERN. Thus, the data analyzed in this study are considered relevant to ongoing clinical use of ERN without laropiprant. This is the first study to compare the effects of ERN/LRPT treatment versus placebo (at 12 weeks) on the relationships between apoB:LDL-C and apoB:non-HDL-C in patients with T2DM. Given the known influence of elevated TG levels on LDL particle composition, these effects were further examined in patient subgroups with higher or lower baseline TG value, using a clinically meaningful cutoff of $<$ and $\geq 2.26 \mathrm{mmol} / \mathrm{L}(200 \mathrm{mg} / \mathrm{dL})$.

\section{Methods}

\section{Study design}

Post-hoc analysis was performed using data from a previously published, worldwide, multicenter (32 sites in the United States and 62 international sites), double-blind, randomized, placebo-controlled, parallel study of dyslipidemic patients with T2DM [36]. The study included a 4week lipid-modifying run-in period followed by a 36-week double-blind treatment period. Complete details regarding study design and patient-entry criteria are published elsewhere (Protocol 069, Clinical Trials.gov: NCT00485758). The study protocol was approved by the institutional review boards at every study center and informed consent was obtained from each subject before the initiation of any study procedures. The study was conducted in accordance with the principles of Good Clinical Practice.

\section{Patients}

Eligible patients included men and women, ages 18 to 80 years, with a diagnosis of T2DM, taking a stable dose of anti-diabetes medication for 3 months prior to study start. Patients had LDL-C $\geq 1.55$ and $<2.97 \mathrm{mmol} / \mathrm{L}$ (greater than or equal to 60 and less than $115 \mathrm{mg} / \mathrm{dL}$ ) and TG $<5.65 \mathrm{mmol} / \mathrm{L}$ (less than $500 \mathrm{mg} / \mathrm{dL}$ ) following a 4-week, lipid-modifying run-in before the randomization visit. Approximately $78 \%$ of patients were taking statins at baseline and were permitted to continue those medications during the study. Patients were excluded if they had the following laboratory values at Visit 1: creatinine $>2.0 \mathrm{mg} / \mathrm{dL}$, creatine kinase (CK) $>2 \times$ the upper limit of normal (ULN), alanine aminotransferase (ALT), aspartate aminotransferase (AST) $>1.5 \times$ ULN, or an abnormal thyroid stimulating hormone level ( $>20 \%$ above the ULN). Other exclusion criteria included $\mathrm{HbA} 1 \mathrm{c}>8.5 \%$ at the screening visit or Visit 1 , recent (new) diagnosis of T2DM or initiation of anti-obesity therapy within 3 months of Visit 1, use of systemic corticosteroids, and cyclical hormone contraceptives or other intermittent hormone therapies in female patients. Permitted lipid-altering therapies included dietary supplement omega-3, HMG-CoA reductase inhibitors ("statins"), fibrates (gemfibrozil, fenofibrate), ezetimibe, ezetimibe/simvastatin combination tablet, and bile-acid sequestrants. Patients taking therapies including niacin (>50 mg/day), Cholestin ${ }^{\mathrm{nm}}$, and fibrates in combination with a statin were excluded.

\section{Treatment}

Patients were randomized 4:3 to ERN/LRPT $1 \mathrm{~g} / 20 \mathrm{mg}$ (1 tablet) or placebo. After 4 weeks of double-blind treatment, doses of active drug and placebo were doubled, increasing the ERN/LRPT to $2 \mathrm{~g} / 40 \mathrm{mg}$ (2 tablets) for the remainder of the study. No adjustments to background lipid-modifying regimens were made for the first 12 weeks of the study.

\section{Clinical laboratory measurements}

A Center for Disease Control-certified laboratory conducted all clinical laboratory analyses using fasting blood samples. Total cholesterol (TC) and TG were measured by enzymatic methods. LDL-C was calculated by use of the Friedewald equation [37]. Non-HDL-C was calculated by subtracting HDL-C from TC values. ApoB was measured in whole plasma by radioimmunoassay and nephelometry.

\section{Statistical methods}

This post-hoc analysis was performed on the subset of patients (90\%; 716/796) who had a baseline and Week 12 or later value for all three variables of interest (i.e., apoB, LDL-C and non-HDL-C). The statistical methods have been described previously in a similar analysis. ${ }^{35} \mathrm{In}$ brief, the analyses were performed in a modified intent-totreat population $(n=768)$ in the full analysis set (FAS) population at Week 12, including all randomized patients who had baseline and at least one post-Week 4 measurements, and had received at least one dose of study medication. Subgroup analyses were performed for patients defined by TG values, as follows: lower, $<2.26 \mathrm{mmol} / \mathrm{L}$ (less than $200 \mathrm{mg} / \mathrm{dL}$, normal to borderline-high TG) and higher, $>2.26 \mathrm{mmol} / \mathrm{L}$ (hypertriglyceridemic).

An analysis of covariance (ANCOVA) model with terms for treatment, country, gender, and corresponding baseline lipid value as covariates was used to compare least squares (LS) mean percent changes from baseline in LDL-C, non-HDL-C and apoB between treatment groups. The placebo-subtracted differences in LS mean percent changes from baseline with $95 \%$ confidence intervals (CI) were estimated from the ANCOVA model.

To examine the linear relationships at baseline and study end (week 12), simple linear regression models with apoB as a response variable were fitted on the overall population who had paired baseline and post-baseline values for apoB and LDL-C and apoB and non-HDL-C. The predicted values of LDL-C and non-HDL-C for known apoB values of $0.8 \mathrm{~g} / \mathrm{L}$ or $0.9 \mathrm{~g} / \mathrm{L}$ were calculated from the models. Pearson correlation coefficients between apoB:LDL-C and apoB:non-HDL-C were computed to inform the strength and direction of the correlations. 
The degree of concordance between apoB:LDL-C and apoB:non-HDL-C were analyzed. Here, each patient was categorized into a quintile for apoB, LDL-C and nonHDL-C; those in the same quintile for the two parameters being compared were considered concordant, whereas those in different quintiles were considered discordant. The weighted kappa statistic was used to quantify the overall degree of concordance between the parameters. The concordance analyses were performed for the overall population and within each treatment group at baseline and endpoint; for each population, the concordance analyses were examined by baseline TG subgroup (i.e., < and $\geq 2.26 \mathrm{mmol} / \mathrm{L}$, or $200 \mathrm{mg} / \mathrm{dL}$ ).

\section{Results}

Approximately $78 \%$ of patients were taking a statin at baseline and continued to receive this treatment throughout the study. The baseline demographic and lipid/lipoprotein characteristics were generally well balanced between the ERN/LRPT and placebo groups in the overall population and within the patient subgroups defined by baseline TG value (Table 1). As expected, patients with higher versus lower baseline TG tended to have lower HDL-C levels and higher apoB, non-HDL-C and total cholesterol levels at baseline. Patients with higher versus lower baseline TG also tended to have higher fasting plasma glucose and glycosylated hemoglobin levels at baseline. Within the higher baseline TG subgroup, a slightly greater proportion of patients in the ERN/LRPT group were not taking a lipid-lowering medication at baseline compared with the placebo group.

In the overall population and within patient subgroups defined by baseline TG, treatment with ERN/LRPT significantly reduced LDL-C, non-HDL-C and apoB versus placebo at Week 12 (Fig. 1). Similar placebo-adjusted reductions of approximately 17, 19 and $17 \%$ were observed for LDL-C, non-HDL-C and apoB, respectively, following treatment with ERN/LRPT in the overall population. The placebo-adjusted decreases in LDL-C, non-HDL-C and apoB were numerically, but not significantly, smaller with ERN/LRPT in the higher versus lower TG subgroup.

Table 1 Baseline characteristics by treatment group

\begin{tabular}{|c|c|c|c|c|c|c|}
\hline \multirow[t]{3}{*}{ Parameter } & \multicolumn{3}{|l|}{$\begin{array}{l}\text { ERN/LRPT } \\
(N=393)\end{array}$} & \multicolumn{3}{|l|}{$\begin{array}{l}\text { Placebo } \\
(N=323)\end{array}$} \\
\hline & \multirow[t]{2}{*}{ Overall Population } & \multicolumn{2}{|c|}{ Baseline TG subgroup } & \multirow[t]{2}{*}{ Overall Population } & \multicolumn{2}{|c|}{ Baseline TG subgroup } \\
\hline & & $\begin{array}{l}<2.26 \mathrm{mmol} / \mathrm{L} \\
(n=320)\end{array}$ & $\begin{array}{l}\geq 2.26 \mathrm{mmol} / \mathrm{L} \\
(n=73)\end{array}$ & & $\begin{array}{l}<2.26 \mathrm{mmol} / \mathrm{L} \\
(n=279)\end{array}$ & $\begin{array}{l}\geq 2.26 \mathrm{mmol} / \mathrm{L} \\
(n=44)\end{array}$ \\
\hline Age, mean $\pm S D, y$ & $61.80 \pm 9.29$ & $62.08 \pm 9.27$ & $60.58 \pm 9.36$ & $61.77 \pm 9.43$ & $62.04 \pm 9.33$ & $60.09 \pm 9.99$ \\
\hline Age, median (range), y & $63(31-79)$ & $63(33-79)$ & $61(31-76)$ & $63(21-80)$ & $63(21-80)$ & $63(36-77)$ \\
\hline \multicolumn{7}{|l|}{ Sex, no. (\%) } \\
\hline Male & $233(59.3)$ & $187(58.4)$ & $46(63.0)$ & $208(64.4)$ & $182(65.2)$ & $26(59.1)$ \\
\hline Female & $160(40.7)$ & $133(41.6)$ & $27(37.0)$ & 115 (35.6) & $97(34.8)$ & $18(40.9)$ \\
\hline \multicolumn{7}{|c|}{ Population subgroups, no. (\%) } \\
\hline Statin-treated & $310(78.9)$ & $259(80.9)$ & $51(69.9)$ & $259(80.2)$ & $227(81.4)$ & $32(72.7)$ \\
\hline Other LMT-treated & $33(8.4)$ & $24(7.5)$ & $9(12.3)$ & $34(10.5)$ & $28(10.0)$ & $6(13.6)$ \\
\hline Drug naive & $72(18.3)$ & $54(16.9)$ & $18(24.7)$ & $55(17.0)$ & $47(16.8)$ & $8(18.2)$ \\
\hline $\mathrm{BMI}$, mean $\pm \mathrm{SD}, \mathrm{kg} / \mathrm{m}^{2}$ & $31.28 \pm 6.45$ & $30.90 \pm 6.43$ & $32.93 \pm 6.34$ & $30.48 \pm 5.83$ & $30.26 \pm 5.92$ & $31.84 \pm 5.01$ \\
\hline \multicolumn{7}{|c|}{ Baseline values, mean \pm SD } \\
\hline apoB, g/L & $0.93 \pm 0.19$ & $0.90 \pm 0.17$ & $1.1 \pm 0.18$ & $0.91 \pm 0.17$ & $0.89 \pm 0.15$ & $1.1 \pm 0.20$ \\
\hline $\mathrm{TC}, \mathrm{mmol} / \mathrm{L}$ & $4.30 \pm 0.68$ & $4.20 \pm 0.67$ & $4.69 \pm 0.58$ & $4.21 \pm 0.64$ & $4.14 \pm 0.60$ & $4.65 \pm 0.75$ \\
\hline Non-HDL-C, mmol/L & $3.00 \pm 0.64$ & $2.85 \pm 0.57$ & $3.64 \pm 0.54$ & $2.91 \pm 0.58$ & $2.81 \pm 0.50$ & $3.53 \pm 0.64$ \\
\hline $\mathrm{HDL}-\mathrm{C}, \mathrm{mmol} / \mathrm{L}$ & $1.29 \pm 0.36$ & $1.35 \pm 0.35$ & $1.04 \pm 0.25$ & $1.30 \pm 0.34$ & $1.33 \pm 0.35$ & $1.12 \pm 0.25$ \\
\hline $\mathrm{LDL}-\mathrm{C}, \mathrm{mmol} / \mathrm{L}$ & $2.26 \pm 0.53$ & $2.26 \pm 0.53$ & $2.27 \pm 0.55$ & $2.20 \pm 0.47$ & $2.19 \pm 0.44$ & $2.27 \pm 0.61$ \\
\hline $\mathrm{TG}^{\mathrm{b}}, \mathrm{mmol} / \mathrm{L}$ & $1.42(0.36-7.10)$ & $1.27(0.36-2.23)$ & $2.88(2.28-7.10)$ & $1.45(0.44-5.75)$ & $1.32(0.44-2.24)$ & $2.63(2.26-5.75)$ \\
\hline$C R P^{b}, \mathrm{mg} / \mathrm{L}$ & $1.8(0.1-56.2)$ & $1.7(0.1-56.2)$ & $2.3(0.3-36.3)$ & $1.5(0.1-69.7)$ & $1.5(0.1-69.7)$ & $1.40(0.3-15.7)$ \\
\hline $\mathrm{FPG}, \mathrm{mmol} / \mathrm{L}$ & $7.29 \pm 1.81$ & $7.10 \pm 1.63$ & $8.11 \pm 2.28$ & $7.41 \pm 1.79$ & $7.38 \pm 1.83$ & $7.62 \pm 1.59$ \\
\hline $\mathrm{HbA} 1 \mathrm{c}, \%$ & $6.91 \pm 0.72$ & $6.86 \pm 0.69$ & $7.11 \pm 0.81$ & $6.90 \pm 0.70$ & $6.89 \pm 0.69$ & $6.97 \pm 0.74$ \\
\hline
\end{tabular}

$A p o B$ apolipoprotein $B ; B M I$ body mass index; ERN/LRPT ER niacin/laropiprant; $H D L-C$ high-density lipoprotein cholesterol; $L D L-C$ low-density lipoprotein cholesterol; TC total cholesterol; TG triglyceride; CRP C-reactive protein; FPG fasting plasma glucose; HbA1c hemoglobin A1c

abecause a patient can be taking both a statin and another LMT at baseline, the total percentage may be greater than $100 \%$

${ }^{b}$ Expressed as median 


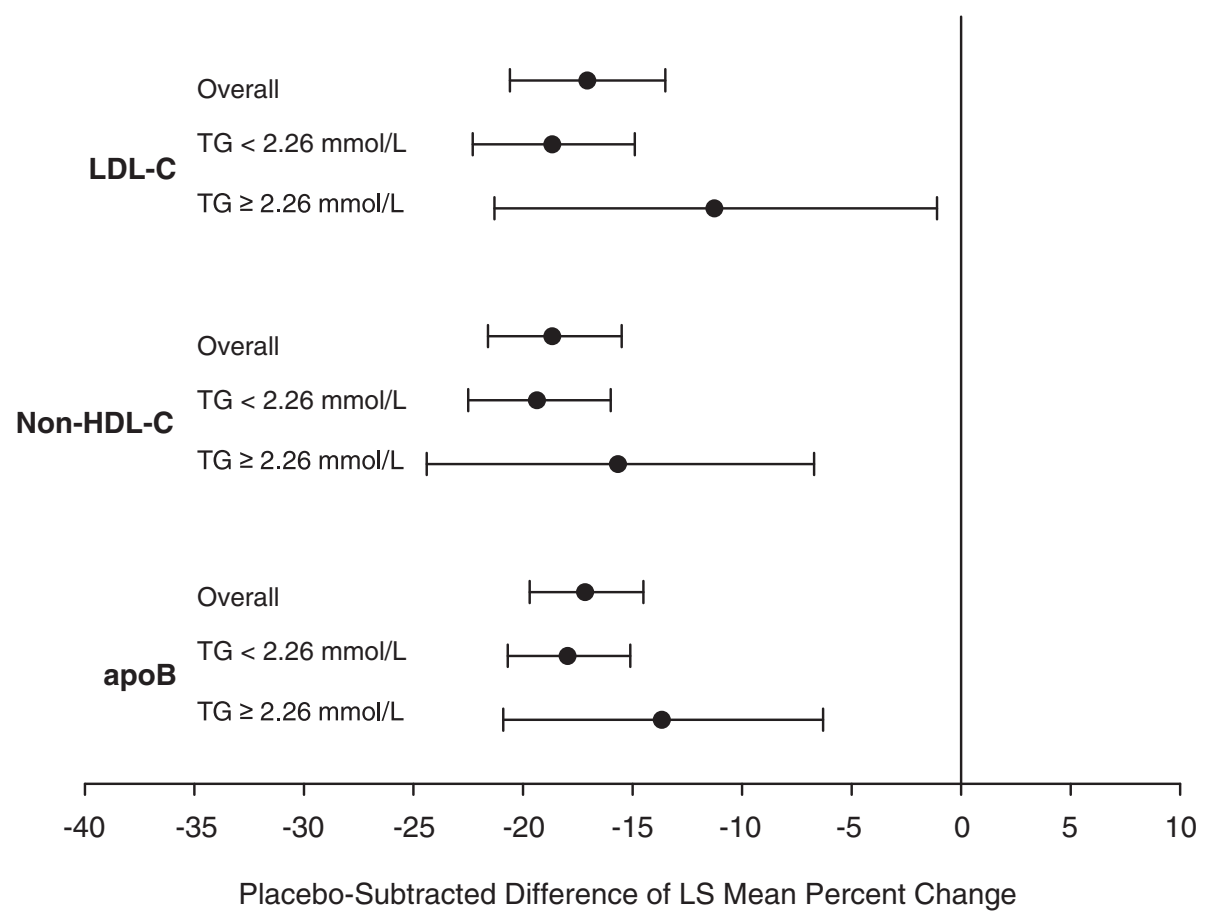

Fig. 1 Between-group differences (with $95 \%$ confidence interval) in least square (LS) mean percentage changes from baseline at Week 12 in LDL-C, non-HDL-C and apoB for the overall population and patient subgroups defined by baseline triglyceride (TG) value (i.e., $<$ and $\geq 2.26 \mathrm{mmol} / \mathrm{L}$ )

Strong positive correlations between apoB:LDL-C and apoB:non-HDL-C were observed at baseline and following treatment with ERN/LRPT or placebo, irrespective of baseline TG level (Table 2; Figs. 2 and 3). Compared with LDL-C, non-HDL-C was more highly correlated with apoB at baseline and Week 12 in the overall population and in both patient subgroups defined by baseline TG. Treatment with ERN/LRPT increased the strength of the correlations between apoB and LDL-C in the overall group and tended to increase the correlations in both lower and high TG groups. ERN/LRPT produced less pronounced increases in the correlations between apoB and non-HDL-C, although the on-treatment correlations were higher than those for apoB and LDL-C (Table 2; Figs. 2 and 3). The improvements in the apoB:LDL-C and apoB:non-HDL-C correlations with ERN/LRPT treatment tended to be greater in the overall population and in the higher versus the lower TG subgroup. The correlations between apoB:LDL-C and apoB:non-HDL-C were generally similar at baseline and study end in the placebo group for the overall population and within both TG subgroups.

At baseline and Week 12, the predicted LDL-C and non-HDL-C values for known apoB values were below the targets of $2.59 \mathrm{mmol} / \mathrm{L}$ and $3.36 \mathrm{mmol} / \mathrm{L}$, respectively (Table 2). When the regression analyses were examined by baseline TG level, the predicted LDL-C values were significantly lower in the high TG versus the low TG subgroup (i.e., $95 \%$ CIs did not overlap) at baseline and Week 12. This finding was observed in both treatment groups, except in the placebo group at Week 12 . In contrast, the predicted non-HDL-C values were significantly greater in the higher versus the lower TG subgroup at baseline, but not at Week 12 .

Weighted kappa statistics to assess the degree of concordance between apoB:LDL-C and apoB:non-HDL-C before and after treatment with ERN/LRPT or placebo are presented in Table 3. A kappa value of 1 represents perfect overlap and a value of 0 represents a complete lack of overlap between 2 parameters. In general, the correlations assessed by Pearson correlation coefficients were corroborated with those assessed by the weighted kappa. For apoB:LDL-C and apoB:non-HDL-C, the weighted kappa values were generally similar between the treatment groups and TG subgroups at baseline. For both treatment groups and both TG subgroups, the weighted kappa values were higher for the comparison of apoB:non-HDL-C versus apoB:LDL-C at baseline and at study end. At baseline, the degree of concordance between apoB and LDL-C was moderate, while the degree of concordance between apoB and non-HDL-C was more substantial. At Week 12, treatment with ERN/LRPT generally increased the level of concordance more between apoB and LDL-C than between apoB and non-HDL-C relative to baseline and placebo. 
Table 2 Slope, intercept, Pearson correlation coefficient, and predicted LDL-C and non-HDL-C values based on simple linear regression of LDL-C or non-HDL-C on apoB at baseline (i.e., prior to receiving randomized treatment) and Week 12

\begin{tabular}{|c|c|c|c|c|c|c|}
\hline Treatment Group & $\mathrm{N}^{\mathrm{a}}$ & Slope & Intercept & $\begin{array}{l}\text { apoB vs LDL-C } \\
\text { Pearson Correlation } \\
\text { Coefficient }(95 \% \mathrm{Cl})\left[\mathrm{R}^{2}\right]\end{array}$ & $\begin{array}{l}\text { Predicted }^{\mathrm{b}} \\
\text { LDL-C Value }(95 \% \mathrm{Cl}) \\
\text { given apoB of } 0.8 \mathrm{~g} / \mathrm{L}\end{array}$ & $\begin{array}{l}\text { Predicted }^{\mathrm{b}} \\
\mathrm{LDL}-\mathrm{C} \text { Value }(95 \% \mathrm{Cl} \text {, } \\
\text { given apoB of } 0.9 \mathrm{~g} / \mathrm{L}\end{array}$ \\
\hline \multicolumn{7}{|c|}{ Baseline (i.e., pre-treatment measurement) } \\
\hline Pooled across treatment groups & 721 & 2.04 & 0.36 & $0.72(069,0.76)[0.53]$ & $1.98(1.95,2.01)$ & $2.18(2.16,2.21)$ \\
\hline $\mathrm{TG}<2.26 \mathrm{mmol} / \mathrm{L}$ & 602 & 2.35 & 0.13 & $0.77(0.74,0.80)[0.59]$ & $2.01(1.98,2.04)$ & $2.24(2.22,2.27)$ \\
\hline $\mathrm{TG} \geq 2.26 \mathrm{mmol} / \mathrm{L}$ & 119 & 2.35 & -0.27 & $0.78(0.70,0.84)[0.61]$ & $1.61(1.50,1.73)$ & $1.85(1.76,1.93)$ \\
\hline ERN/LRPT & 395 & 2.04 & 0.35 & $0.73(0.68,0.77)[0.53]$ & $1.99(1.94,2.03)$ & $2.19(2.15,2.23)$ \\
\hline $\mathrm{TG}<2.26 \mathrm{mmol} / \mathrm{L}$ & 322 & 2.43 & 0.07 & $0.80(0.75,0.83)[0.64]$ & $2.02(1.98,2.06)$ & $2.26(2.23,2.30)$ \\
\hline $\mathrm{TG} \geq 2.26 \mathrm{mmol} / \mathrm{L}$ & 73 & 2.22 & -0.16 & $0.74(0.61,0.83)[0.55]$ & $1.63(1.47,1.79)$ & $1.85(1.73,1.98)$ \\
\hline Placebo & 326 & 1.99 & 0.38 & $0.72(0.66,0.76)[0.51]$ & $1.98(1.93,2.02)$ & $2.18(2.14,2.21)$ \\
\hline $\mathrm{TG}<2.26 \mathrm{mmol} / \mathrm{L}$ & 280 & 2.20 & 0.23 & $0.72(0.66,0.78)[0.53]$ & $2.00(1.96,2.04)$ & $2.22(2.18,2.26)$ \\
\hline $\mathrm{TG} \geq 2.26 \mathrm{mmol} / \mathrm{L}$ & 46 & 2.51 & -0.41 & $0.85(0.73,0.91)[0.72]$ & $1.59(1.43,1.75)$ & $1.84(1.71,1.97)$ \\
\hline \multicolumn{7}{|l|}{ Week 12} \\
\hline ERN/LRPT & 394 & 2.30 & 0.04 & $0.82(0.79,0.85)[0.68]$ & $1.88(1.84,1.91)$ & $2.11(2.07,2.15)$ \\
\hline $\mathrm{TG}<2.26 \mathrm{mmol} / \mathrm{L}$ & 321 & 2.61 & -0.16 & $0.84(0.80,0.87)[0.70]$ & $1.93(1.90,1.97)$ & $2.20(2.15,2.24)$ \\
\hline $\mathrm{TG} \geq 2.26 \mathrm{mmol} / \mathrm{L}$ & 73 & 1.99 & 0.13 & $0.86(0.78,0.91)[0.74]$ & $1.73(1.65,1.81)$ & $1.93(1.86,2.00)$ \\
\hline Placebo & 323 & 2.09 & 0.27 & $0.73(0.68,0.78)[0.54]$ & $1.94(1.89,1.98)$ & $2.14(2.07,2.15)$ \\
\hline $\mathrm{TG}<2.26 \mathrm{mmol} / \mathrm{L}$ & 279 & 2.35 & 0.06 & $0.77(0.71,0.81)[0.59]$ & $1.94(1.89,1.98)$ & $2.17(2.13,2.21)$ \\
\hline $\mathrm{TG} \geq 2.26 \mathrm{mmol} / \mathrm{L}$ & 44 & 1.68 & 0.50 & $0.69(0.49,0.82)[0.47]$ & $1.84(1.66,2.02)$ & $2.01(1.86,2.15)$ \\
\hline Treatment Group & $\mathrm{N}^{\mathrm{a}}$ & Slope & Intercept & $\begin{array}{l}\text { apoB vs non-HDL-C } \\
\text { Pearson Correlation } \\
\text { Coefficient ( } 95 \% \text { Cl) [R2] }\end{array}$ & $\begin{array}{l}\text { Predicted }^{\mathrm{b}} \\
\text { Non-HDL-C Value } \\
(95 \% \mathrm{Cl}) \text { given } \\
\text { apoB of } 0.8 \mathrm{~g} / \mathrm{L}\end{array}$ & $\begin{array}{l}\text { Predicted }^{\mathrm{b}} \\
\text { Non-HDL-C Value } \\
(95 \% \mathrm{Cl}) \text { given } \\
\text { apoB of } 0.9 \mathrm{~g} / \mathrm{L}\end{array}$ \\
\hline \multicolumn{7}{|c|}{ Baseline (i.e., pre-treatment measurement) } \\
\hline Pooled across treatment groups & 721 & 2.97 & 0.21 & $0.87(0.85,0.89)[0.76]$ & $2.59(2.56,2.62)$ & $2.89(2.87,2.91)$ \\
\hline $\mathrm{TG}<2.26 \mathrm{mmol} / \mathrm{L}$ & 602 & 2.82 & 0.31 & $0.84(0.82,0.87)[0.71]$ & $2.57(2.54,2.60)$ & $2.85(2.83,2.88)$ \\
\hline $\mathrm{TG} \geq 2.26 \mathrm{mmol} / \mathrm{L}$ & 119 & 2.59 & 0.81 & $0.85(0.79,0.89)[0.72]$ & $2.88(2.78,2.98)$ & $3.14(3.06,3.21)$ \\
\hline ERN/LRPT & 395 & 2.95 & 0.25 & $0.87(0.85,0.89)[0.76]$ & $2.61(2.57,2.65)$ & $2.90(2.87,2.94)$ \\
\hline $\mathrm{TG}<2.26 \mathrm{mmol} / \mathrm{L}$ & 322 & 2.82 & 0.32 & $0.86(0.83,0.89)[0.74]$ & $2.58(2.54,2.61)$ & $2.86(2.83,2.89)$ \\
\hline $\mathrm{TG} \geq 2.26 \mathrm{mmol} / \mathrm{L}$ & 73 & 2.38 & 1.07 & $0.81(0.71,0.87)[0.65]$ & $2.97(2.83,3.10)$ & $3.20(3.10,3.31)$ \\
\hline Placebo & 326 & 3.00 & 0.17 & $0.87(0.84,0.89)[0.75]$ & $2.57(2.53,2.61)$ & $2.87(2.84,2.90)$ \\
\hline $\mathrm{TG}<2.26 \mathrm{mmol} / \mathrm{L}$ & 280 & 2.82 & 0.30 & $0.82(0.78,0.86)[0.67]$ & $2.56(2.52,2.60)$ & $2.84(2.81,2.88)$ \\
\hline $\mathrm{TG} \geq 2.26 \mathrm{mmol} / \mathrm{L}$ & 46 & 2.87 & 0.46 & $0.91(0.83,0.95)[0.82]$ & $2.76(2.62,2.90)$ & $3.05(2.94,3.15)$ \\
\hline \multicolumn{7}{|l|}{ Week 12} \\
\hline ERN/LRPT & 394 & 3.28 & -0.13 & $0.89(0.87,0.91)[0.79]$ & $2.49(2.45,2.53)$ & $2.82(2.78,2.86)$ \\
\hline $\mathrm{TG}<2.26 \mathrm{mmol} / \mathrm{L}$ & 321 & 3.15 & -0.06 & $0.87(0.84,0.90)[0.76]$ & $2.47(2.43,2.51)$ & $2.78(2.74,2.83)$ \\
\hline $\mathrm{TG} \geq 2.26 \mathrm{mmol} / \mathrm{L}$ & 73 & 3.36 & -0.12 & $0.88(0.82,0.92)[0.78]$ & $2.56(2.44,2.68)$ & $2.89(2.78,3.00)$ \\
\hline Placebo & 323 & 3.21 & -0.04 & $0.87(0.84,0.90)[0.76]$ & $2.52(2.48,2.56)$ & $2.84(2.80,2.88)$ \\
\hline $\mathrm{TG}<2.26 \mathrm{mmol} / \mathrm{L}$ & 279 & 3.00 & 0.12 & $0.85(0.82,0.88)[0.73]$ & $2.52(2.48,2.57)$ & $2.82(2.79,2.86)$ \\
\hline $\mathrm{TG} \geq 2.26 \mathrm{mmol} / \mathrm{L}$ & 44 & 3.60 & -0.33 & $0.89(0.79,0.93)[0.78]$ & $2.55(2.35,2.75)$ & $2.91(2.75,3.07)$ \\
\hline
\end{tabular}




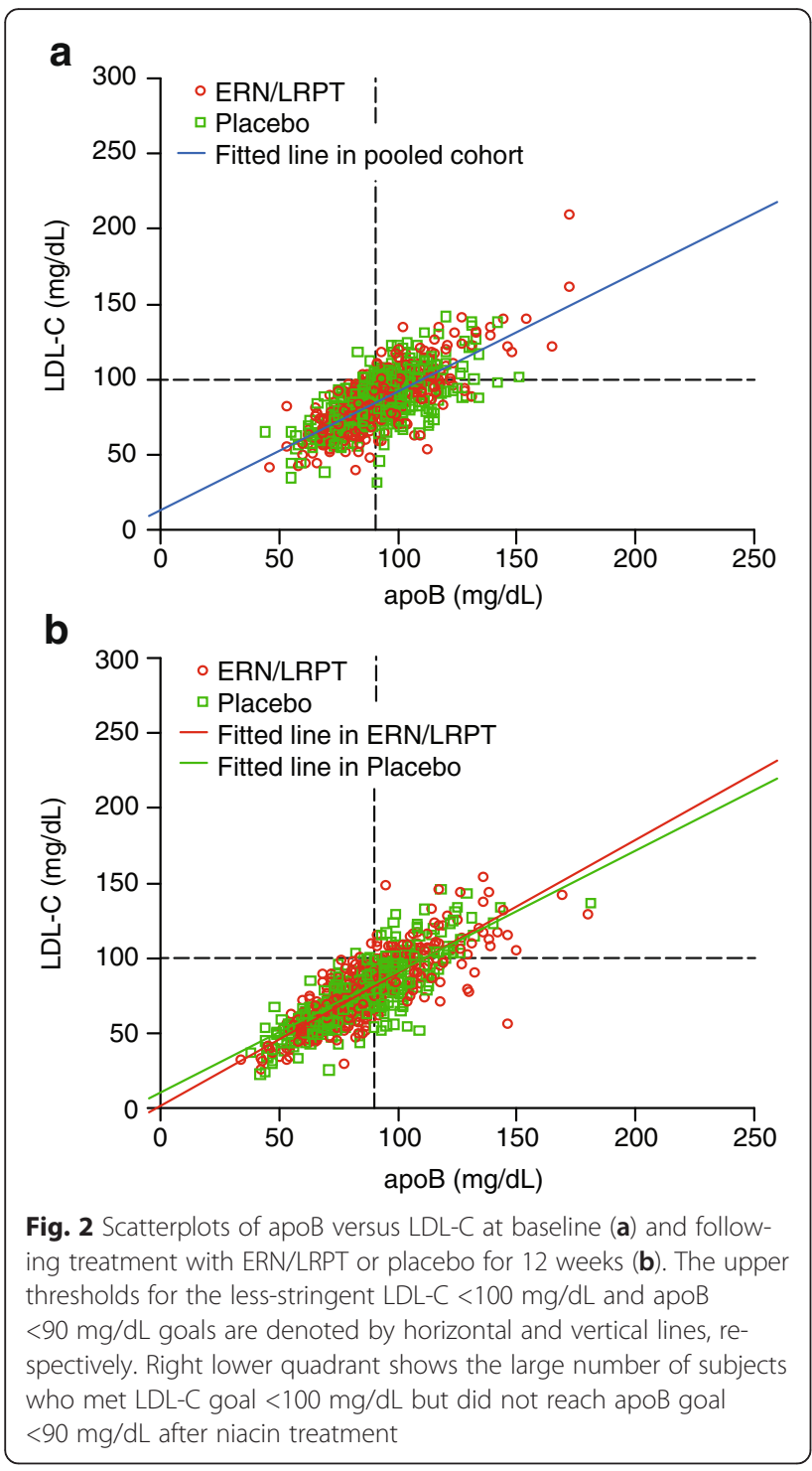

\section{Discussion}

The influence of statin therapy on the correlations between apoB:LDL-C and apoB:non-HDL-C in dyslipidemic patients has been well studied [30-34]. Statin therapy produces smaller percentage reductions in apoB than in LDL-C and non-HDL-C. Further, statin therapy strengthens the linear relationships between apoB:LDL-C and apoB: non-HDL-C, as evidenced by increases in the correlation coefficients and kappa values (i.e., a measure of the degree of concordance between 2 parameters) for these parameters in statin-treated versus untreated patients. Although the influence of non-statin lipid-modifying drugs on the linear relationships between these lipid/lipoprotein parameters has been less well studied, a recent analysis evaluated the effects of ERN/LRPT, simvastatin (SIMVA), and ERN/LRPT + SIMVA on apoB:LDL-C and apoB: non-HDL-C correlations in patients with dyslipidemia
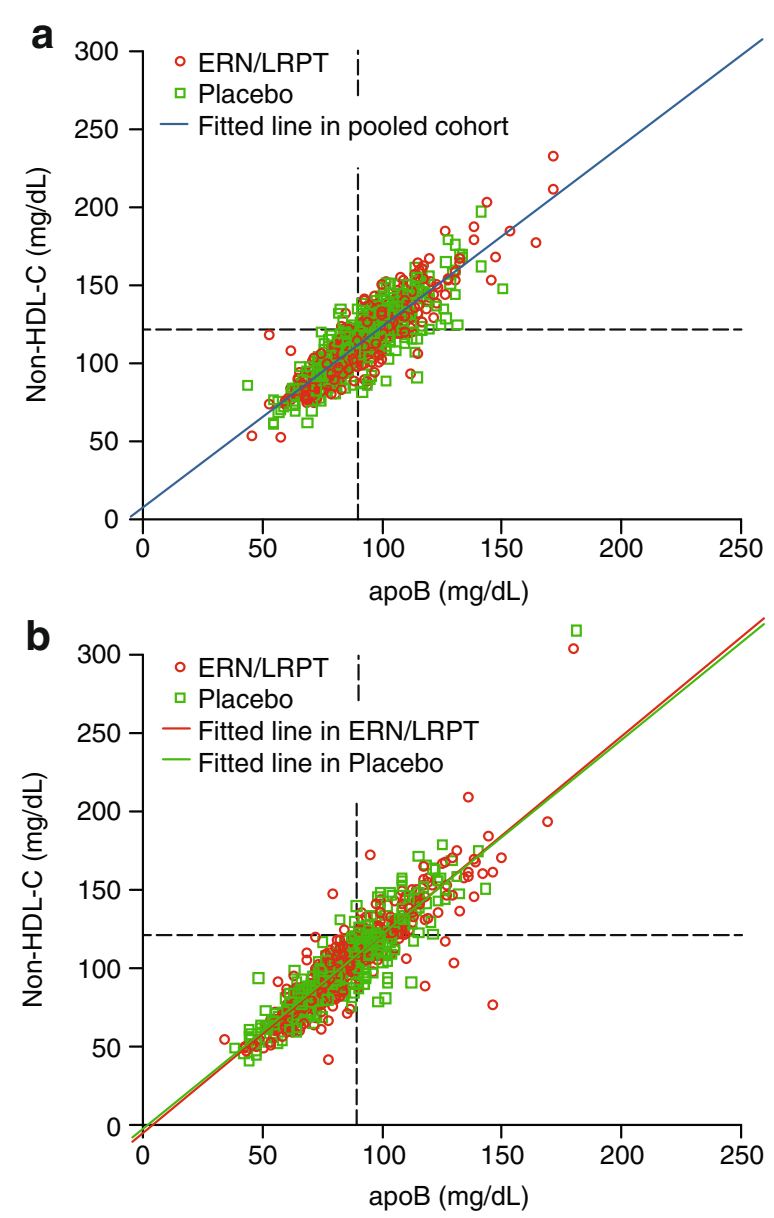

Fig. 3 Scatterplots of apoB versus non-HDL-C at baseline (a) and following treatment with ERN/LRPT or placebo at Week 12 (b). The upper thresholds for the less-stringent non-HDL-C $<130 \mathrm{mg} / \mathrm{dL}$ and apoB $<90 \mathrm{mg} / \mathrm{dL}$ goals are denoted by horizontal and vertical lines, respectively. Right lower quadrant shows the large number of subjects who met non-HDL-C goal $<130 \mathrm{mg} / \mathrm{dL}$ but did not reach apoB goal $<90 \mathrm{mg} / \mathrm{dL}$ after niacin treatment

[35]. The results demonstrated that both LDL-C and non-HDL-C were well correlated with apoB at baseline and following treatment with ERN/LRPT, SIMVA and the combination of both, and the correlations were higher and the predicted LDL-C and non-HDL-C levels based on apoB were considerably lower compared with baseline [35].

The primary purpose of the present analysis was to examine the effects of ERN/LRPT on the relationships (i.e., correlation coefficients, linear regression analyses and kappa values) between apoB:LDL-C and apoB:non-HDL-C in patients with T2DM. At baseline, approximately $78 \%$ of patients were receiving statin-based (non-niacin) lipid-modifying therapy and were permitted to continue these medications throughout the study. Thus, these analyses examine the effects of ERN/LRPT on relationships between apoB:LDL-C and apoB:non-HDL-C in T2DM 
Table 3 Degree of concordance among apoB, LDL-C, and non-HDL-C levels at baseline and study endpoint in the pooled treatment groups for the overall population and treatment subgroups defined by baseline $\mathrm{TG}<$ and $\geq 2.26 \mathrm{mmol} / \mathrm{L}$

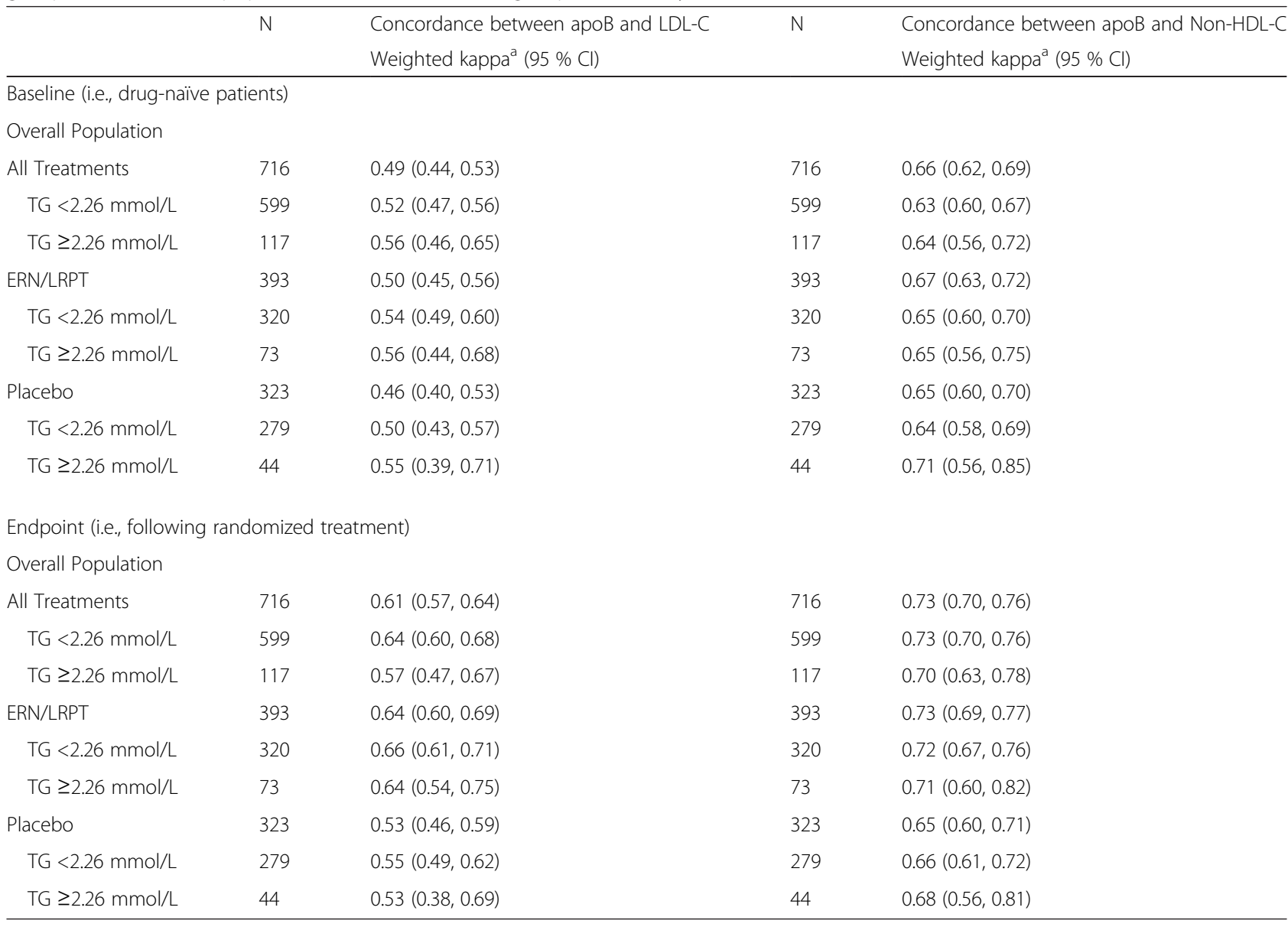

ERN/LRPT niacin/laropiprant; $a p o B$ apolipoprotein $B$ DL-C low-density lipoprotein cholesterol; $H D L-C$ high-density lipoprotein cholesterol; TG triglyceride ${ }^{a}$ The $\mathrm{k}$ statistic, on a scale from 0 to 1 , reflects the degree of agreement between two variables. The levels of agreement range from slight $(0-0.20)$, fair $(0.21-0.40)$, moderate $(0.41-0.60)$, substantial $(0.61-0.80)$, and almost perfect $(0.81-1.00)$

patients, the majority of whom were taking a statin-based therapy. Given the known influence of TG levels on LDL particle composition, the relationships between these lipid/lipoprotein parameters were also examined at baseline and following treatment in subgroups of patients with lower and higher baseline TG values.

Treatment with ERN/LRPT produced similar magnitude reductions from baseline in apoB, LDL-C and non-HDL-C in patients with T2DM (i.e., mean reductions ranging from 17 to $19 \%$ across the lipid/lipoprotein parameters). A trend toward smaller magnitude reductions in apoB, LDL-C and non-HDL-C were observed in patients with higher versus lower baseline TG values ( $\geq$ and $<2.26 \mathrm{mmol} / \mathrm{L}$ ). Nevertheless, similar magnitude mean percent reductions from baseline in apoB, LDL-C and non-HDL-C were observed when the treatment effects were examined separately within each of the TG subgroups. Overall, the findings of the current study support prior study results, showing that treatment with ERN/LRPT and ERN (without LRPT) produces somewhat comparable reductions in
apoB, LDL-C and non-HDL-C in patients with dyslipidemia [38]. This study, for the first time, extends these findings to include patients with T2DM, irrespective of baseline TG level. In contrast, studies of statin monotherapy show significantly larger magnitude reductions in LDL-C and non-HDL-C versus apoB in a wide variety of patient populations, including those with T2DM and hypertriglyceridemia $[19,28]$. The differential effects of ERN compared with statins on apoB, LDL-C and non-HDL-C are likely due to differences in the mechanisms of actions of these agents.

This analysis demonstrated strong, linear relationships between apoB:LDL-C and apoB:non-HDL-C, both at baseline and following treatment with ERN/LRPT. Treatment with ERN/LRPT increased the strengths of the correlation coefficients between apoB:LDL-C, with a less pronounced effect on apoB:non-HDL-C. The strengths of the correlations between apoB:LDL-C and apoB:non-HDL-C were generally stronger in the higher versus the lower TG subgroup. 
For the overall population, the predicted LDL-C and non-HDL-C levels corresponding to known apoB values at baseline were already below the targets of $2.59 \mathrm{mmol} / \mathrm{L}$ and $3.36 \mathrm{mmol} / \mathrm{L}$, respectively, and these levels were further lowered following treatment with ERN/LRPT. When examined by TG subgroup, the predicted LDL-C values were lower in the higher TG versus the lower TG subgroup, both at baseline and study endpoint. Conversely, the predicted non-HDL-C values were higher in the high TG versus the lower TG subgroup at baseline, but this finding was less pronounced at study endpoint.

ApoB was more concordant with non-HDL-C than with LDL-C, both at baseline and study endpoint, irrespective of the TG subgroup. This was expected since apoB is a measure of the number of non-HDL particles. Treatment with ERN/LRPT increased the concordance between apoB:non-HDL-C less than that between apoB:LDL-C, although the former remained higher than the latter.

\section{Conclusion}

In conclusion, the apoB:LDL-C and apoB:non-HDL-C correlation coefficients and kappa values were higher and the predicted LDL-C and non-HDL-C levels for a known apoB value were lower following treatment with ERN/LRPT compared with baseline levels. Interestingly, this was despite the fact that there were greater percent decreases in LDL-C and non-HDL-C than in apoB. Although some discordance remains between non-HDL-C and apoB levels, these data suggest that there may be only modest benefit from measurement of apoB in addition to the non-HDL-C level available as part of the standard lipid panel. These data also show the attainment of more aggressive LDL-C and non-HDL-C goals in patients receiving ERN in combination with a statin, reminding of the potential of combination lipid-modifying therapy for further reduction of coronary risk by helping to normalize apoB-containing atherogenic lipoprotein composition and levels.

\section{Acknowledgments}

The authors would like to thank Jennifer Rotonda, Kristen Lewis, and Carol Zecca of Merck \& Co., Inc., Kenilworth, NJ for their assistance with preparing this manuscript for publication.

\section{Funding}

Funding for this study was provided by Merck \& Co., Inc., Kenilworth, NJ.

\section{Authors' contribution}

$E A B, J T, P B, E C, A O J-L, C M S, R A R, A A M, D M$, and YBM are responsible for the work described in this paper. All authors were involved in at least one of the following: conception, design, acquisition, analysis, statistical analysis, and interpretation of data in addition to drafting the manuscript and/or revising/ reviewing the manuscript for important intellectual content. All authors provided final approval of the version to be published. All authors agree to be accountable for all aspects of the work in ensuring that questions related to the accuracy or integrity of any part of the work are appropriately investigated and resolved.

\section{Competing interest}

E. Brinton has received consultant/speaker honoraria and/or research grants from Merck \& Co., Inc., Amarin, Abbott, Arisaph, Aegerion, Atherotech, AstraZeneca, Essentialis, Janssen, Kowa, Lilly, Amgen, Novartis, Sanofi-Aventis, and Takeda. No honorarium was paid for E. Brinton's work in preparing and writing this manuscript, although technical assistance was provided as noted under Acknowledgements. J. Triscari, P. Brudi, E. Chen, A.O. Johnson-Levonas, C. McCrary Sisk, R.A. Ruck, A.A. MacLean, D. Maccubbin, Y.B. Mitchel are current or former employees of Merck \& Co., Inc., Kenilworth, NJ and may own stock and/or hold stock options in the company.

\section{Author details}

'Division of Atherometabolic Research, Utah Foundation for Biomedical Research, 420 Chipeta Way, Room 1160, Salt Lake City, UT 84108, USA. ${ }^{2}$ Merck \& Co., Inc., Kenilworth, NJ, USA.

Received: 3 May 2016 Accepted: 23 June 2016

Published online: 12 July 2016

\section{References}

1. Go AS, Mozaffarian D, Roger VL, et al. Heart disease and stroke statistics-2014 update: a report from the American Heart Association. Circulation. 2014;129:399-410.

2. ADA. Dyslipidemia management in adults with diabetes. Diabetes Care. 2004;27:S68-71.

3. Manzato E, Zambon A, Lapolla A, et al. Lipoprotein abnormalities in well-treated type II diabetic patients. Diabetes Care. 1993;16:469-75.

4. Third Report of the National Cholesterol Education Program (NCEP) Expert Panel on Detection, Evaluation, and Treatment of High Blood Cholesterol in Adults (Adult Treatment Panel III) final report. Circulation. 2002;106: 3143-21.

5. Brunzell JD, Davidson M, Furberg CD, et al. Lipoprotein management in patients with cardiometabolic risk: consensus statement from the American Diabetes Association and the American College of Cardiology Foundation. Diabetes Care. 2008;31:811-22.

6. Davidson $\mathrm{MH}$, Ballantyne $\mathrm{CM}$, Jacobson TA, et al. Clinical utility of inflammatory markers and advanced lipoprotein testing: advice from an expert panel of lipid specialists. J Clin Lipidol. 2011:5:338-67.

7. Genest J, McPherson R, Frohlich J, et al. 2009 Canadian Cardiovascular Society/Canadian guidelines for the diagnosis and treatment of dyslipidemia and prevention of cardiovascular disease in the adult - 2009 recommendations. Can J Cardiol. 2009;25:567-79.

8. Catapano AL, Reiner Ž, De Backer G, et al. ESC/EAS Guidelines for the management of dyslipidaemias: The Task Force for the management of dyslipidaemias of the European Society of Cardiology (ESC) and the European Atherosclerosis Society (EAS). Atherosclerosis. 2011;217:1-44.

9. Stone NJ, Robinson J, Lichtenstein AH, et al. 2013 ACC/AHA guideline on the treatment of blood cholesterol to reduce atherosclerotic cardiovascular risk in adults: a report of the American College of Cardiology/American Heart Association Task Force on practice guidelines. J Am Coll Cardiol. 2014;65:2889-934.

10. Endocrinology Group Rejects New AHA/ACC CVD Guidelines. Medscape. Dec 13, 2013.

11. NLA Statement on the 2013 ACC/AHA Guideline on the Treatment of Blood Cholesterol to Reduce Atherosclerotic Cardiovascular Risk in Adults. Available at: https://www.lipid.org/nla/2013-accaha-quideline-treatment-bloodcholesterol-reduce-atherosclerotic-cardiovascular-risk. Accessed 7 July 2016.

12. Expert Dyslipidemia Panel of the International Atherosclerosis Society. An International Atherosclerosis Society Position Paper: global recommendations for the management of dyslipidemia-full report. J Clin Lipidol. 2014;8:29-60.

13. Gibbons GH, Shurin SB, Mensah GA, Lauer MS. Refocusing the agenda on cardiovascular guidelines: an announcement from the National Heart, Lung, and Blood Institute. J Am Coll Cardiol. 2013;15:1396-8.

14. Boekholdt SM, Arsenault BJ, Mora S, et al. Association of LDL cholesterol, non-HDL cholesterol, and apolipoprotein B levels with risk of cardiovascular events among patients treated with statins: a meta-analysis. JAMA. 2012:307:1302-9.

15. Ingelsson E, Schaefer EJ, Contois JH, et al. Clinical utility of different lipid measures for prediction of coronary heart disease in men and women. JAMA. 2007;298:776-85.

16. Liu J, Sempos CT, Donahue RP, Dorn J, Trevisan M, Grundy SM. Nonhigh-density lipoprotein and very-low-density lipoprotein cholesterol 
and their risk predictive values in coronary heart disease. Am J Cardiol. 2006;98:1363-8

17. Pischon T, Girman CJ, Sacks FM, Rifai N, Stampfer MJ, Rimm EB. Non-highdensity lipoprotein cholesterol and apolipoprotein B in the prediction of coronary heart disease in men. Circulation. 2005;112:3375-83.

18. Robinson JG, Wang S, Smith BJ, Jacobson TA. Meta-analysis of the relationship between non-high-density lipoprotein cholesterol reduction and coronary heart disease risk. J Am Coll Cardiol. 2009;53:316-22.

19. Sniderman $A D$, Williams $K$, Contois $J H$, et al. A meta-analysis of low-density lipoprotein cholesterol, non-high-density lipoprotein cholesterol, and apolipoprotein B as markers of cardiovascular risk. Circ Cardiovasc Qual Outcomes. 2011;4:337-45.

20. Davidson MH. Reducing residual risk for patients on statin therapy: the potential role of combination therapy. Am J Cardiol. 2005;96:3K-13K.

21. Guyton JR, Goldberg AC, Kreisberg RA, Sprecher DL, Superko R, O'Connor CM. Effectiveness of once-nightly dosing of extended-release niacin alone and in combination for hypercholesterolemia. Am J Cardiol. 1998;82:737-43.

22. The Coronary Drug Project Research Group. Clofibrate and niacin in coronary heart disease. JAMA. 1975;231:360-81.

23. Brown $B G$, Zhao $X-Q$, Chait $A$, et al. Simvastatin and niacin, antioxidant vitamins, or the combination for the prevention of coronary disease. N Engl J Med. 2001;345:1583-92.

24. Taylor AJ, Sullenberger LE, Lee HJ, Lee JK, Grace KA. Arterial biology for the investigation of the treatment effects of reducing cholesterol (ARBITER) 2. A double-blind, placebo-controlled study of extended-release niacin on atherosclerosis progression in secondary prevention patients treated with statins. Circulation. 2004;110:3512-7.

25. The AIM-HIGH Investigators. Niacin in patients with low HDL cholesterol levels receiving intensive statin therapy. N Engl J Med. 2011;365:2255-67.

26. HPS2-THRIVE Collaborative Group. Effects of extended-release niacin with laropiprant in high-risk patients. N Engl J Med. 2014;371:203-12.

27. Guyton JR, Slee AE, Anderson T, et al. Relationship of Lipoproteins to Cardiovascular Events: The AIM-HIGH Trial (Atherothrombosis Intervention in Metabolic Syndrome With Low HDL/High Triglycerides and Impact on Global Health Outcomes). J Am Coll Cardiol. 2013;62:1580-4.

28. Ballantyne CM, Andrews TC, Hsia JA, Kramer JH, Shear C. Correlation of non-high-density lipoprotein cholesterol with apolipoprotein B: effect of 5 hydroxymethylglutaryl coenzyme A reductase inhibitors on non-high-density lipoprotein cholesterol levels. Am J Cardiol. 2001;88:265-9.

29. Ballantyne CM, Raichlen JS, Cain VA. Statin therapy alters the relationship between apolipoprotein $B$ and low-density lipoprotein cholesterol and non-high-density lipoprotein cholesterol targets in high-risk patients: the MERCURY II (Measuring Effective Reductions in Cholesterol Using Rosuvastatin) trial. J Am Coll Cardiol. 2008;52:626-32.

30. Charlton-Menys V, Betteridge DJ, Colhoun $\mathrm{H}$, et al. Targets of statin therapy: LDL cholesterol, non-HDL cholesterol, and apolipoprotein B in type 2 diabetes in the Collaborative Atorvastatin Diabetes Study (CARDS). Clin Chem. 2009;55:473-80.

31. Idris I, Tate H, Ahmad A, McCormack T. Concordance between plasma apolipoprotein B levels and cholesterol indices among patients receiving statins and nonstatin treatment: Post-hoc analyses from the U.K. InPractice study. J Clin Lipidol. 2011;5:316-23.

32. Grundy SM, Vega GL, Tomassini JE, Tershakovec AM. Correlation of nonhigh-density lipoprotein cholesterol and low-density lipoprotein cholesterol with apolipoprotein B during simvastatin + fenofibrate therapy in patients with combined hyperlipidemia (a subanalysis of the SAFARI trial). Am J Cardiol. 2009;104:548-53.

33. Farnier M, Taggart W, Dong Q, Lin J, Shah A, Brudi P. Influence of simvastatin, fenofibrate and/or ezetimibe on correlation of $L D L$ and non-HDL cholesterol with apolipoprotein B in mixed dyslipidemic patients. J Clin Lipidol. 2011:5:179-87.

34. Farnier M, Guyton JR, Jensen E, Polis AB, Johnson-Levonas AO, Brudi P. Effects of Ezetimibe, simvastatin and ezetimibe/simvastatin on correlations between apolipoprotein $\mathrm{B}, \mathrm{LDL}$ cholesterol and non $\mathrm{HDL}$ cholesterol in patients with primary hypercholesterolemia. Atherosclerosis. 2013;229:415-22.

35. Farnier M, Chen E, Johnson-Levonas AO, McCrary Sisk C, Mitchel YB. Effects of extended-release niacin/laropiprant, simvastatin, and the combination on correlations between apolipoprotein B, LDL cholesterol, and non-HDL cholesterol in patients with dyslipidemia. Vasc Health Risk Manag. 2014;10:279-90.

36. MacLean A, McKenney JM, Scott R, et al. Efficacy and safety of extendedrelease niacin/laropiprant in patients with type 2 diabetes mellitusBr. J Cardiol. 2011;18:37-45
37. Fridewald WT, Levy RI, Fredrickson DS. Estimation of the concentration of low-density lipoprotein cholesterols in plasma, without use of the preparative ultracentrifuge. Clin Chem. 1972;18:499-502.

38. Maccubbin $D$, Bays $H E$, Olsson AG, et al. Lipid-modifying efficacy and tolerability of extended release niacin/laropiprant in patients with primary hypercholesterolaemia or mixed dyslipidaemia. Int J Clin Pract. 2008;62:1959-70,

\section{Submit your next manuscript to BioMed Central and we will help you at every step:}

- We accept pre-submission inquiries

- Our selector tool helps you to find the most relevant journal

- We provide round the clock customer support

- Convenient online submission

- Thorough peer review

- Inclusion in PubMed and all major indexing services

- Maximum visibility for your research

Submit your manuscript at www.biomedcentral.com/submit
) Biomed Central 